\title{
Functional Expression and Regulation of Hyperpolarization-Activated Cyclic Nucleotide-Gated Channels (HCN) in Mouse iPS Cell-derived Cardiomyocytes after UTF1-Neo Selection
}

\author{
Judith Semmler ${ }^{a}$ Martin Lehmann ${ }^{a}$ Kurt Pfannkuche ${ }^{a}$ Michael Reppela,b \\ Jürgen Hescheler ${ }^{\mathrm{a}}$ Filomain $\mathrm{Nguemo}^{\mathrm{a}}$ \\ anstitute of Neurophysiology, University of Cologne, Cologne, bDepartment of Cardiology, \\ Medical University of Lübeck, Lübeck, Germany
}

\section{Key Words}

Induced pluripotent stem cells - Cardiomyocytes - Heart development - Hyperpolarizationactivated cation channel $\bullet$ Whole-cell patch-clamp

\begin{abstract}
Background/Aims: In vitro reprogramming of somatic cells holds great potential to serve as an autologous source of cells for tissue repair. However, major difficulties in achieving this potential include obtaining homogeneous and stable cells for transplantation. High electrical activity of cells such as cardiomyocytes (CMs) is crucial for both, safety and efficiency of cell replacement therapy. Moreover, the function of the cardiac pacemaker is controlled by the activities of hyperpolarization-activated cyclic nucleotide-gated (HCN) channels. Here we have examined changes in HCN gene expression and function during cardiomyogenesis. Methods: We differentiated murine iPS cells selected by an undifferentiated transcription factor 1 (UTF 1) -promoter-driven $\mathrm{G} 418$ resistance to CMs in vitro and characterized them by RT-PCR, immunocytochemistry, and electrophysiology. Results: As key cardiac markers alpha-actinin and cardiac troponin T could be identified in derived CMs. Immunocytochemical staining of CMs showed the presence of all HCN subunits (HCN1-4). Electrophysiology experiments revealed developmental changes of action potentials and $I_{f}$ currents as well as functional hormonal regulation and sensitivity to $l_{f}$ channel blockers. Conclusion: We conclude that iPS cells derived from UTF-selection give rise to functional CMs in vitro, with established hormonal regulation pathways and functionally expressed $I_{f}$ current in a development-dependent manner; and have all phenotypes with the pacemaker as predominant subtype. This might be of great importance for transplantation purposes.
\end{abstract}




\section{Introduction}

The constant demand for donor organs makes cardiomyoplasty an interesting treatment alternative for failing hearts that respond poorly to pharmacological treatment [1]. Although cell transplantation has modestly improved cardiac function, major goals including increasing cell numbers and quality, cell survival, engraftment, and functional integration into host tissue have to be met. Induced pluripotent stem cells (iPSCs) that can be generated from a patient's own fibroblasts can differentiate into spontaneously beating cardiomyocyte (CM) clusters within embryoid bodies (EBs). While recapitulating developmental stages of embryonic cardiomyogenesis, iPSCs also represent a candidate source for cardiac cell therapy [2, 3]. To replace embryonic stem cells (ESCs) with iPSCs for transplantation purposes, analysis and comparison of their properties are crucial. Furthermore, it is not known which specific cell type or which condition of cell differentiation and specialization is most appropriate for transplantations. This problem is exacerbated by the lack of techniques to produce a huge amount of cells and of strategies to screen the large numbers of parameters affecting cell therapy. Recent progress in genetic engineering has raised interest in the early development of the mouse heart, but the initiation of electrical and contractile activity in mammalian hearts is still not completely understood. The hyperpolarization-activated cation current $\left(I_{\mathrm{f}}\right)$ and the hyperpolarization-activated cyclic nucleotide-modulated (HCN) subunits that underlie it are important components of spontaneous activity and modulate the rate of the murine embryonic heart [4]. The degree of activation of the $I_{\mathrm{f}}$ current determines the frequency of action potential (AP) firing. In the heart, $I_{\mathrm{f}}$ is found in the Purkinje fibers and in pacemaker (nodal)- as well as in ventricular- and atrial-like cells, where it is believed to mediate the $ß$-adrenergic stimulation and muscarinergic modulation of the heart rate via direct modulation by cAMP [5]. In mammalian heart cells, the HCN channel family comprises four distinct members (HCN1-4) that underlie the native $I_{\mathrm{f}}$ current. In contrast to other members of this superfamily, voltage-gated HCN channels open upon membrane hyperpolarization. By conducting a mixed inward current of monovalent cations $\left(\mathrm{K}^{+}, \mathrm{Na}^{+}\right)$, the channels cause the membrane to depolarize [6]. However, there are differences in the tissue expression and in the activation properties of each isoform. In the rabbit sinoatrial node (SAN), for example, HCN1 is highly expressed, whereas HCN2 is the dominant isoform in atrial and ventricular myocytes [7]. The HCN3 isoform is expressed at a low level in cardiac cells compared with HCN4, which is a major subtype expressed, particularly in the murine SAN [7-9]. Regarding their activation properties, HCN1 and HCN4 are associated with a depolarized voltage threshold, with HCN1 displaying the most positive voltage for the activation of $I_{\mathrm{f}^{\prime}}$ HCN2 and HCN3 are correlated with a more negative threshold [10,11]. Among other reasons, differences in HCN functionality can be explained by differences in regional expression levels. During cardiomyogenesis, the expression levels of the subunits change considerably [12]. To investigate the relationship between HCN channel alterations and pacemaker activity, different mouse transgenic models have been developed [13]. In mammalian heart disease, mutations of HCN channels exert a crucial influence on this rhythmicity. Mutations near the cAMP-binding site induced decreases of the inward diastolic current and, thus, the heart rate. Other mutations in HCN have been shown to cause dysfunctions of the HCN channel [13-15]. While the presence of the $I_{\mathrm{f}}$ current in murine ESC (mESC)-derived CMs is well established [16], a closer investigation of this current in CMs derived from murine iPSCs (miPSCs), especially from those generated with different techniques (e.g., retrovirus or lentiviral introduction), is still lacking. Because of the spontaneous beating activity of miPSC CMs, we focused our analysis on the If currents. This study deals with changes in HCN protein expression and $I_{\mathrm{f}}$ channel activity and sensitivity to specific blockers in CMs derived from miPSCs selected for pluripotency by the UTF1-promoter, which has been shown to generate homogenous and stable pluripotent iPSCs [17]. Functional binding sites for Oct4 and Sox2, the M1 genetic element, important for Nanog expression within the enhancer region of the UTF1-promoter, and possible additional yet unknown factors provide rapid inactivation upon induction of cell differentiation [17-19]. Because UTF1 is down-regulated 
faster than other pluripotency markers during this differentiation, UTF1-selection might help to select for uniform, high-quality pluripotent cells, which are a prerequisite for conclusive measurements [17]. We found that culturing miPSCs generated after UTF1 transfection resulted in higher yields of CMs that expressed all four HCN genes in a differentiation stagedependent manner. Moreover, we used the current- and voltage-clamp configurations of the whole-cell patch-clamp technique to record APs and $I_{\mathrm{f}}$ currents in the same CMs. We found the presence of all three main pacemaker cell phenotypes, namely, nodal-like, atrial-like, and ventricular-like cells, based on their AP shapes. We analyzed the AP parameters and the hormonal regulation of the spontaneous electrical activity in miPS CMs. The investigation of the basic biophysical properties of $I_{\mathrm{f}}$ revealed a high density of the $I_{\mathrm{f}}$ current in EDS CMs which was decreased in CMs of LDS. Additionally, the AP parameters of iPS cell-derived CMs generated after UTF1 transfection were comparable with those of CMs generated from ESCs with respect to the stage of differentiation. Therefore, this approach may provide the basis for future optimization of HCN-based biological pacemakers and cell-based heart therapies.

\section{Material and Methods}

\section{Cell Culture and in vitro differentiation}

For our study, the miPS cell line TiB7-4 kindly provided by Rudolf Jaenisch's (Whitehead Institute of Technology, MA, USA) [19] was used. TiB7-4 miPSCs were transfected with an UTF1-promoter-driven G418 ("Neo") resistance and enriched for stable pluripotent phenotypes as described. An alpha-myosin heavy chain $(\alpha M H C)$-promoter-driven puromycin resistance was introduced in order to purify miPS-CMs after differentiation [17]. The mES cell line D3- $\alpha$ PIG44, carrying a puromycin-resistance ( $\alpha M H C$-promoter) and expressing eGFP [20], was used as control. To maintain their undifferentiated state, mESCs and miPSCs were grown on irradiated, mitotically inactive murine embryonic fibroblasts (MEFs) and cultured with $1 \mathrm{U} / \mu \mathrm{l} \mathrm{LIF}$ (leukemia inhibitory factor, ESGRO, Millipore, Billerica, MA, USA). The MEFs were attained from Him:OF1 outbred mice at embryonic day 14.5 and mitotically inactivated by mitomycin C treatment $(10 \mu \mathrm{g} / \mathrm{ml}$, SERVA Electrophoresis $\mathrm{GmbH}$ ). Murine ES and iPS cell cultures were performed as previously described [2, 17]. Briefly, the differention medium was composed of Iscove's modified Eagle medium (IMDM) supplemented with $17 \%$ fetal calf serum (FCS), $100 \mathrm{U} / \mathrm{ml}$ penicillin and $100 \mathrm{mg} / \mathrm{ml}$ streptomycin, $1 \%$ nonessential amino acids (NEAA), $0.1 \mathrm{mmol} / \mathrm{l} \beta$-mercaptoethanol (all purchased from Invitrogen). Adherent confluent cells were passaged every 2 days by enzymatical dissociation with $0.05 \%$ trypsin/EDTA (Invitrogen) for $5 \mathrm{~min}$ at $37^{\circ} \mathrm{C}$ and $5 \% \mathrm{CO}_{2}$.

Cardiac differentiation of miPS and mES cells was performed in mass culture as previously described [2] with the addition of ascorbic acid ( $3 \mathrm{mg} / \mathrm{ml}$ ) from day 0 to day 3 of differentiation [21]. Colonies of undifferentiated cells (Fig. 1A) were dissociated into single cells with $0.05 \%$ trypsin/EDTA (Invitrogen) for $5 \mathrm{~min}$ at $37^{\circ} \mathrm{C}$ and $5 \% \mathrm{CO}_{2}$. Thereafter, $1 \times 10^{6}$ cells were suspended in $12 \mathrm{ml}$ Iscove's modified Dulbecco's medium (IMDM), supplemented with $17 \%$ fetal calf serum (FCS), $100 \mathrm{U} / \mathrm{ml}$ penicillin, $100 \mu \mathrm{g} / \mathrm{ml}$ streptomycin, $1 \%$ nonessential amino acids, and $0.1 \mathrm{mM} \beta$-mercaptoethanol, and placed on a horizontal shaker at $37^{\circ} \mathrm{C}$ and $5 \% \mathrm{CO}_{2}$. On day 2 of differentiation, cells were diluted to $1000 \mathrm{EBs} /$ dish and further agitated. Beating areas were first detected at day 8 of differentiation. Early developmental stage (EDS) was defined according to the day of differentiation when the majority of EBs started beating (day 10-11), intermediate developmental stage (IDS) two to three days later (day 13) and late developmental stage (LDS) as differentiation on day 15. For immunostaining and whole-cell patch-clamp experiments, single CMs were prepared as previously described [22].

\section{RT-PCR Analysis}

Total RNA was isolated from undifferentiated cells or beating EBs at day 11,13, and 15 of differentiation using TRIzol Reagent (Invitrogen). $2 \mu \mathrm{g}$ of total RNA from each sample were reverse transcribed into cDNA using the Superscript VILO cDNA synthesis kit with Superscript III Reverse transcriptase (Invitrogen). 5 $\mu \mathrm{l}$ of each cDNA were applied as template to detect the expression levels of HCN1, HCN2, HCN3, and HCN4 subunits using the DreamTaq Green DNA polymerase kit (Thermo Scientific) in a total reaction volume of $20 \mu \mathrm{l}$. PCR cycling conditions were: Initial denaturation at $94^{\circ} \mathrm{C}$ for $2 \mathrm{~min}$ and $94^{\circ} \mathrm{C}$ for $35 \mathrm{~s}$ with each 
cycle, annealing at $60^{\circ} \mathrm{C}$ for $45 \mathrm{~s}$ and extension at $72^{\circ} \mathrm{C}$ for $45 \mathrm{~s}$ for a total of 32 cycles. Final extension was at $72^{\circ} \mathrm{C}$ for $5 \mathrm{~min}$. GAPDH (Glycinaldehyde-3-phosphate dehydrogenase) was used as housekeeping control gene in all RT-PCR reactions. Following sets of intron-spanning primers were used (forward and reverse, respectively): HCN1: TCAAGGAGGCAGTATCAAGAGAAG and ACCGAAAGGGAGTAAAGACGAC, HCN2: ACTGCCCGCTGGACTTCC and ATCTCCTTGTTGCCCTTGGT, HCN3: CACCGCCCTCATCCAGTC and CCCTCACGCACCACCAG, HCN4: TTTCATCTCCTCCATCCCTGTC and CCTGCCGTCCATACCCAAT, and GAPDH: GTGTTCCTACCCCCAATGTG and CTTGCTCAGTGTCCTTGCTG. All primers were obtained from Invitrogen. Amplificated products were run on $1 \%$ agarose gels with ethidium bromide and were imaged using UV light (UV system, Intas). The relative intensities of HCN isoform bands were quantified with the help of the software ImageJ 1.45. The obtained values were normalized with GAPDH as external control gene.

\section{Immunocytochemical staining}

Colonies of undifferentiated mES and miPS cells and differentiated EBs (on day 11, day 13, and day 15) were dissociated into single cells and small cell clusters, plated on $0.1 \%$ gelatin-coated cover slips and cultured for up to 3 days at $37^{\circ} \mathrm{C}$ and $5 \% \mathrm{CO}_{2}$. Thereafter, samples were fixed with $4 \%$ paraformaldehyde for $20 \mathrm{~min}$ at room temperature (RT). Subsequently, cells were permeabilized with $0.5 \mathrm{M} \mathrm{NH}_{4} \mathrm{Cl}$ and $0.25 \%$ Triton X-100 (Sigma-Aldrich) in 1\% bovine serum albumin for $20 \mathrm{~min}$, rinsed 3 times for 5 min with DPBS (Invitrogen), and blocked with Roti-Immunoblock (Roth) for 60 min at RT. Samples were incubated overnight at $4{ }^{\circ} \mathrm{C}$ with primary antibodies diluted in Roti-Immunoblock (Roth). Negative controls were processed in exactly the same way, but in Roti-Immunoblock (Roth) without any primary antibody during the incubation. The preparations were subsequently incubated with appropriate secondary antibodies for $2 \mathrm{~h}$ at RT. Nuclei were counterstained with Hoechst 33342 (1:2000, Sigma-Aldrich). After washing, samples were embedded in ProLong Gold Antifade Reagent and evaluated using a Zeiss Axiovert 200 epifluorescence microscope. For analysis the Zeiss AxioVision 4.5 software package (Zeiss, Göttingen, Germany) was applied. The following primary antibodies were used: Mouse monoclonal $\operatorname{IgG}_{1}$ anti sarcomeric $\alpha$-actinin antibody (1:800, SigmaAldrich), mouse monoclonal $\mathrm{IgG}_{1}$ anti-cardiac troponin $\mathrm{T}$ (cardiac isoform) antibody (1:500, Thermo Scientific), mouse monoclonal IgG $\mathrm{I}_{1}$ anti-caveolin 3 antibody (1:500, BD Biosciences), rabbit polyclonal IgG $\alpha$-HCN1(1:100), $\alpha$-HCN2(1:200), $\alpha$-HCN3 (1:200), and $\alpha$-HCN4 (1:100) (Alomone Labs, Jerusalem, Israel). Secondary antibodies were: Alexa Fluor 555 goat anti-mouse (for $\alpha$-actinin, troponin T, Caveolin 3), and Alexa Fluor 488 rabbit anti-mouse (Invitrogen) (for HCN1 through HCN4), each at 1:1000 dilution.

\section{Electrophysiological experiments}

For electrophysiological measurements EBs were enzymatically dissociated $(0.25 \%$ trypsin and $0.05 \%$ EDTA, $5 \mathrm{~min}, 37^{\circ} \mathrm{C}$ and $5 \% \mathrm{CO}_{2}$ ) and seeded on glass cover slips ( $\left.22 \times 22 \mathrm{~mm}\right)$. Measurements were performed after $48 \mathrm{~h}$ of incubation on individual CMs that were selected according to their morphology and spontaneous beating activity. The CMs were recorded using the whole-cell configuration of the patch-clamp technique [23]. The EPC-9 amplifier (Heka electronics, Lambrecht/Pfalz, Germany) was applied for signal enhancement. The PULSE/PULSEFIT program (Heka) was used for data acquisition and analyses. Leak subtraction was applied online in all experiments. The zero current was set by subtracting the DC (direct current) leak current based on the data points corresponding to the first stored segment. Pipettes (3-5 $\mathrm{M} \Omega$ resistance when filled with standard intracellular solution) were made from thin walled borosilicate glass capillaries tubes (World Precision Instruments WPI) on a Zeitz DMZ Universal Puller (DMZ). Glass coverslips with attached single cells were transferred into a recording chamber and placed upon the stage of an Axiovert 135 TV inverted microscope (Zeiss). During measurements cells were constantly superfused using a gravitational perfusion system with a perfusion rate of about $2 \mathrm{ml}$ per min. The bath temperature was held constant at $37^{\circ} \mathrm{C}$. After establishment of the giga-ohmic seal, membrane capacitance $\mathrm{C}_{\mathrm{m}}$ and series resistance $R_{\text {series }}$ were compensated to minimize the capacitive transient. Only cells showing stable values were included in the analysis. APs were recorded in current clamp mode and $I_{\mathrm{f}}$-currents in voltage clamp mode. To measure APs and $I_{\mathrm{f}}$ from the same cell, respectively, the patch-clamp mode was switched from current clamp to voltage clamp. The drugs used here were diluted to the required concentration in external solution and applied via the perfusion system. CMs were assigned to a distinct subtype according to the measured membrane potential, the upstroke velocity and the AP duration. For $I_{\mathrm{f}}$ recording, hyperpolarizing steps from a holding potential of $-55 \mathrm{mV}(20 \mathrm{~ms})$ to the range of -135 to $+35 \mathrm{mV}$ ( $360 \mathrm{~ms}$ each) in 10 $\mathrm{mV}$-steps were applied to determine conductance-voltage relationships. The currents were normalized by 
membrane capacitance to reduce variability in amplitude due to variations in cell surface area. Data were digitized at $10 \mathrm{kHz}$, filtered at $1 \mathrm{kHz}$, and stored on hard disk.

\section{Experimental solutions}

The experimental external solution (Tyrode solution) contained (in $\mathrm{mM}$ ): $\mathrm{NaCl} 140, \mathrm{KCl} 5.4, \mathrm{CaCl}_{2} 1.8$, $\mathrm{MgCl}_{2} 1$, D-glucose 10 and $N$-2-hydroxyethylpiperazine- $N$ '-2-ethanesulfonic acid (HEPES) 10, adjusted to pH 7.4 with $\mathrm{NaOH} . \mathrm{BaCl}_{2} 2, \mathrm{NiCl}_{2} 2$, and 4-aminopyridine 0.5 were added to the external solution to reduce the interference of other components. Internal pipette solution contained (in $\mathrm{mM}$ ): $\mathrm{KCl} 50, \mathrm{~K}$-aspartate 80, $\mathrm{MgCl}_{2}$ 1, EGTA 10, MgATP 3, HEPES 10, adjusted to pH 7.4 with $\mathrm{KOH}$. CsCl (Sigma-Aldrich) was applied 10 mM solubilized in Tyrode solution. ZD 7288 (Tocris biosciences, UK) was made up as stock solution of 10 $\mathrm{mM}$ in water, and was appropriately diluted in Tyrode solution to give final concentration of $10 \mu \mathrm{M}$ [24].

\section{Data analysis}

From the I-V relations, specific conductance of $I_{\mathrm{f}}$ was determined for each cell according to the equation $\mathrm{g}=\mathrm{I} /\left(\mathrm{V}_{\mathrm{m}}-\mathrm{V}_{\text {rev }}\right)$, where $\mathrm{g}$ is the conductance calculated from the current amplitude $\mathrm{I}$, the membrane potential $\mathrm{V}_{\mathrm{m}}$, and the reversal potential $\mathrm{V}_{\text {rev }}$. The numbers stated in the figures indicate the amount of measured cells or EBs, respectively, if not mentioned elsewise in the legends.

Results were expressed as mean \pm SEM. Paired student's t-test was used for statistical analysis. Values with $\mathrm{P}<0.05$ were considered as statistically significant $\left({ }^{*}\right)$.

\section{Results}

Differentiation of murine ES and iPS cells towards spontaneously beating cardiomyocytes To investigate the maturation process towards the formation of typical growing cell clusters called embryoid bodies (EBs), we induced cell differentiation of miPSCs towards CMs in the presence of $3 \mathrm{mg} / \mathrm{ml}$ ascorbic acid. During the differentiation process, the EBs started to contract spontaneously from day 8 onwards. The morphology of miPSC-EBs was similar to this of mESC-EBs (Fig. 1A, left panel). However, miPSC-derived EBs showed a significant growth delay at the early stage of differentiation compared with the mESC-EBs (triplicates experiment, $\mathrm{P}<0.05$ ) (Fig. $1 \mathrm{~A}$, right panel). At EDS, the size of miPSC-EBs was $109 \pm 14 \mu \mathrm{m}^{2}(\mathrm{n}=12)$, and the size of mESC-EBs was $209 \pm 26 \mu \mathrm{m}^{2}(\mathrm{n}=14)$. However, both cell types showed similar EB sizes at LDS (miPSCs: $511 \pm 40 \mu \mathrm{m}^{2}(\mathrm{n}=12)$, mESCs: $490 \pm 35 \mu \mathrm{m}^{2}$ $(n=9))$. To assess the efficacy of miPSC differentiation toward CMs, 1000 EBs were cultured and monitored daily for the presence of contractions for up to 15 days after initiation of the differentiation, respectively (Fig. 1B). The percentage of miPSC-EBs displaying contracting areas at day 8 or 9 was nearly $100 \%$ and remained constant over the course of differentiation. The percentage of beating EBs derived from mESCs differed significantly at all observed days and first showed the highest amount of beating EBs at day $10(\sim 64 \%)$ of differentiation and declined to $\sim 23 \%$ at day 15 . Furthermore, we performed immunocytochemical staining to proof the cardiomyogenic differentiation potential of UTF1-Neo selected miPSCs. The presence of cardiac-specific proteins and their structural organization were studied in dispersed single cells derived from contracting EBs. Figure 1C shows representative positive staining of the myocytes with cardiac-specific $\alpha$-actinin and troponin T. Both proteins were strongly expressed in day $15 \mathrm{CMs}$ generated from mESCs and miPSCs. The high-resolution images (Fig. 1C, inserts) revealed the presence of CMs with well-organized and similar cross striation, indicative of a regular sarcomeric pattern organization.

Functional characterization of CMs derived from UTF1-selected miPSC differentiation

To investigate the electrophysiological properties and the integrity of CMs derived from miPSCs after UTF1 selection, the current-clamp method was used to record APs in single cells. In all three stages of differentiation (EDS, IDS, and LDS), we detected APs of all 3 major CM- subtypes, namely, nodal-, atrial-, and ventricular-like cells (Fig. 2A, representative records; and Fig. 2B, percentage of subtype-appearance). The AP subtypes were classified 


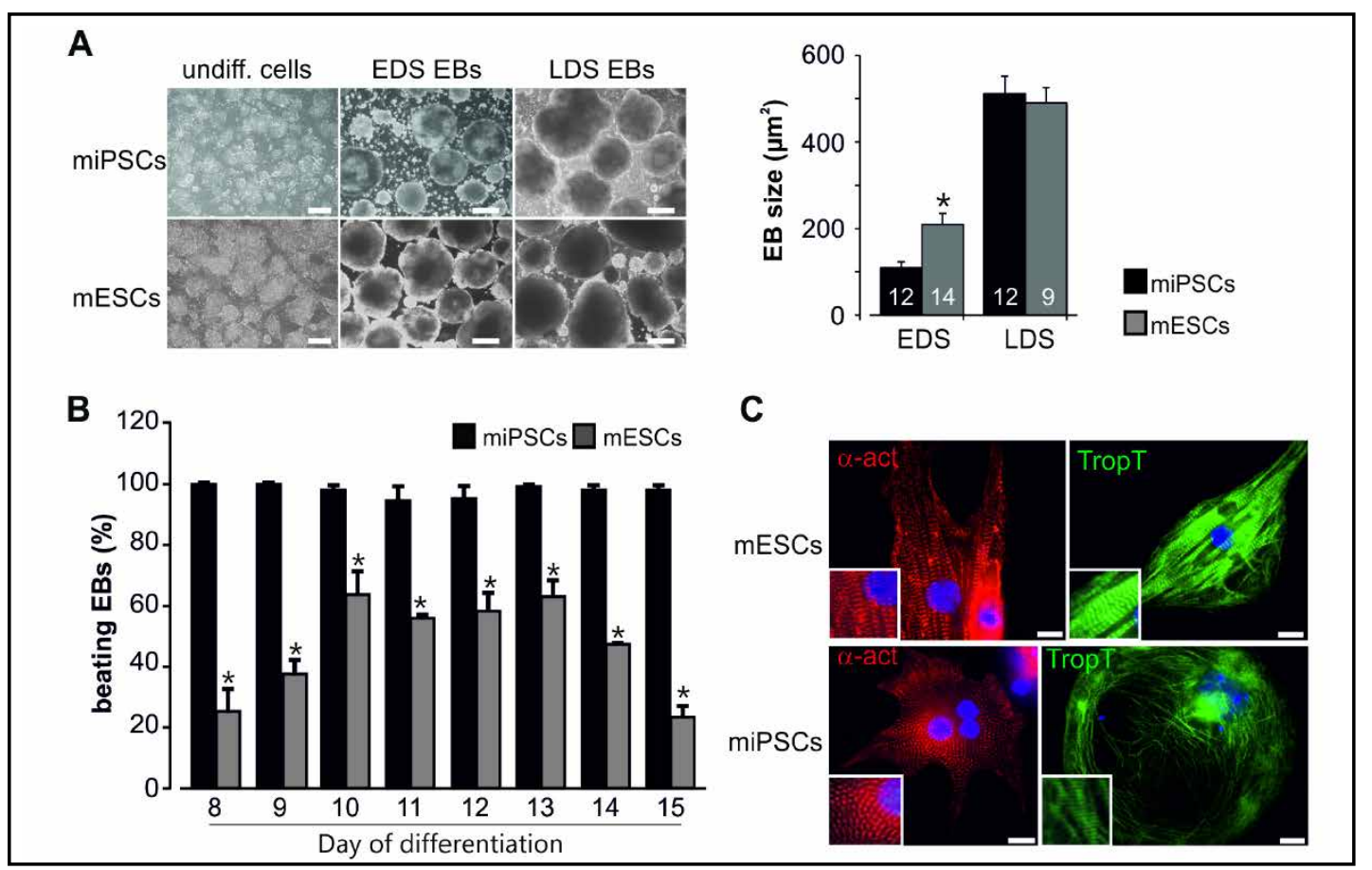

Fig. 1. In vitro differentiation of miPSCs (TiB7-4) and mESCs (D3- $\alpha$ PIG44) into CMs. (A) Left: Adherent cell layer of undifferentiated miPSCs and mESCs followed by embryoid bodies at early (EDS, day 11) and late (LDS, day 15) developmental stages (scale bars: undiff. cells: $100 \mu \mathrm{M}$, EBs: $500 \mu \mathrm{m}$ ); Right: Size analysis of EBs in EDS and LDS. (B) The percentage of beating EBs assessed on each day of differentiation in 10 (miPSCs) and 8 (mESCs) independent experiments (composed of 1000 EBs each). (C) Confocal images of single miPS-CMs and mESC-CMs stained with $\alpha$-actinin (red) and troponin T (green) antibodies. Nuclei were stained with Hoechst 33342 (blue) (scale bar: $10 \mu \mathrm{m}$ ); inserts show the typical cardiac cross-striation. Data are expressed as the mean $\pm \mathrm{SEM},{ }^{*} \mathrm{P}<0.05$ vs. miPSC-derived EBs.

according to their maximum diastolic potential (MDP), amplitude (APA), beating frequency (Rate), upstroke velocity $\left(V_{\max }\right)$, and action potential duration (APD) at $30 \%, 50 \%$, and $90 \%$ of repolarization (summarized in Table 1) as previously described [25]. At EDS, 21, 31, and $48 \%$ of APs for atrial-, nodal-, and ventricular-like cells, respectively, could be identified (Fig. 2B). The amount of atrial and ventricular cells decreased at IDS (14\%, 45\%, respectively) and both changed to $30 \%$ at LDS. The percentage of nodal cells increased with differentiation to $41 \%$ at IDS and stayed relatively constant (40\%) at LDS. Spontaneous AP parameters of CMs derived from miPSCs at LDS were comparable with control mESC-derived CMs of the same stage of differentiation [26]. Cardiac cells generated from miPSCs at EDS showed mostly irregular beating pattern, and they featured slightly variable AP shapes from cell to cell. Table 1 shows that the AP amplitudes (APAs) of all measured cells were relatively constant during differentiation despite relatively small fluctuations in the membrane potential. The maximal diastolic potential (MDP) of atrial- and ventricular-like CMs increased over the course of differentiation, while the MDP of nodal cells stayed constant. From EDS to LDS the spontaneous beating rates increased significantly in atrial, nodal, and ventricular CMs. Accordingly, the maximal velocity of depolarization $\left(V_{\max }\right)$ also showed an increasing tendency with differentiation in all cardiac cell types. In nodal-like cells of EDS and LDS, $V_{\max }$ was clearly lower than in atrial- and ventricular-like cells. AP durations (APDs) for all three cell types decreased significantly during the differentiation (Table 1).

To assess the functional integrity of the CMs (intact response to hormones, transmitters of the central nervous system, and the $\beta$-adrenergic and muscarinic signaling pathways), we determined the effect of isoproterenol (Iso) and carbachol (Cch) on CMs at EDS and LDS. Figure 2C and 2D illustrate the effect of both drugs on the AP frequency. The application of 
Table 1. AP characteristics of miPSC-derived CMs. Electrophysiological patch-clamp measurements manifest AP parameters verifying atrial, nodal, and ventricular cardiac AP shapes. Data are expressed as the mean $\pm \mathrm{SEM},{ }^{*} \mathrm{P}<0.05$; numbers in brackets indicate the number of measured cells

\begin{tabular}{|c|c|c|c|c|c|c|c|c|c|}
\hline & \multicolumn{3}{|c|}{ EDS } & \multicolumn{3}{|c|}{ IDS } & \multicolumn{3}{|c|}{ LDS } \\
\hline & $\begin{array}{c}\mathrm{a} \\
(20)\end{array}$ & $\begin{array}{c}\mathrm{n} \\
(24)\end{array}$ & $\begin{array}{c}\mathrm{v} \\
(37)\end{array}$ & $\begin{array}{c}a \\
(4)\end{array}$ & $\begin{array}{c}\mathrm{n} \\
(12)\end{array}$ & $\begin{array}{c}\mathrm{v} \\
(13)\end{array}$ & $\begin{array}{c}a \\
(24)\end{array}$ & $\begin{array}{c}n \\
(28)\end{array}$ & $\begin{array}{c}\mathrm{v} \\
(30)\end{array}$ \\
\hline MDP (mV) & $-64 \pm 1$ & $-53 \pm 2$ & $-61 \pm 1$ & $-64 \pm 3$ & $-52 \pm 2$ & $-50 \pm 3$ & $-52 \pm 2$ & $-52 \pm 1$ & $-59 \pm 2$ \\
\hline APA (mV) & $96 \pm 3$ & $73 \pm 4$ & $94 \pm 2$ & $92 \pm 5$ & $75 \pm 3$ & $92 \pm 3$ & $93 \pm 2$ & $76 \pm 3$ & $94 \pm 3$ \\
\hline Rate (bpm) & $348 \pm 43$ & $248 \pm 20$ & $216 \pm 14$ & $370 \pm 53$ & $267 \pm 26$ & $208 \pm 17$ & $584 \pm 26^{*}$ & $389 \pm 31 *$ & $481 \pm 40^{*}$ \\
\hline $\operatorname{Vmax}(\mathrm{V} / \mathrm{s})$ & $25 \pm 2$ & $7 \pm 1$ & $18 \pm 2$ & $25 \pm 4$ & $7 \pm 2$ & $18 \pm 5$ & $29 \pm 2$ & $11 \pm 2$ & $21 \pm 2$ \\
\hline APD $30(\mathrm{~ms})$ & $29 \pm 5$ & $52 \pm 7$ & $91 \pm 2$ & $35 \pm 5$ & $38 \pm 3$ & $85 \pm 6$ & $26 \pm 3$ & $30 \pm 2^{*}$ & $63 \pm 11 *$ \\
\hline APD $50(\mathrm{~ms})$ & $50 \pm 7$ & $79 \pm 9$ & $118 \pm 12$ & $45 \pm 5$ & $56 \pm 5$ & $106 \pm 7$ & $36 \pm 4$ & $47 \pm 3 *$ & $78 \pm 12 *$ \\
\hline APD $90(\mathrm{~ms})$ & $115 \pm 15$ & $155 \pm 11$ & $245 \pm 28$ & $98 \pm 11$ & $159 \pm 18$ & $209 \pm 31$ & $68 \pm 9 *$ & $124 \pm 15^{*}$ & $148 \pm 25^{*}$ \\
\hline
\end{tabular}

A

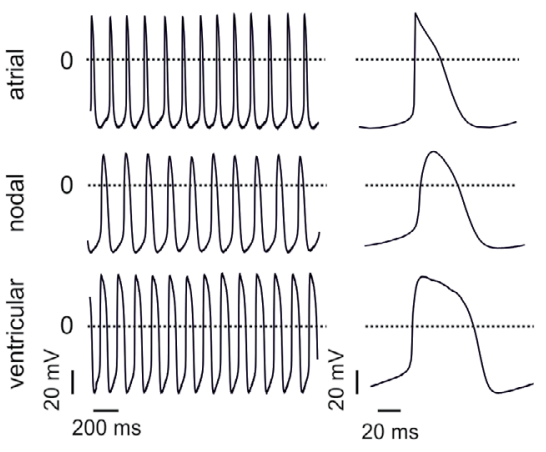

C
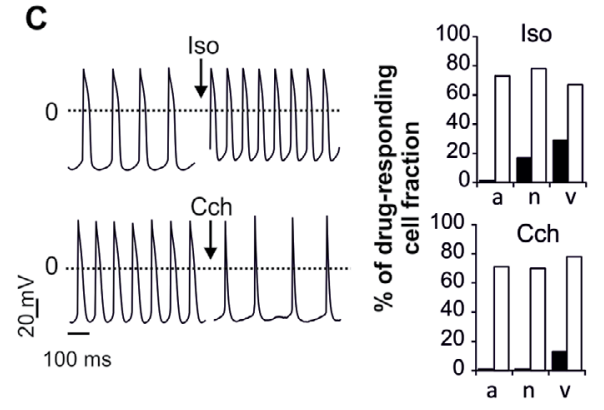

B

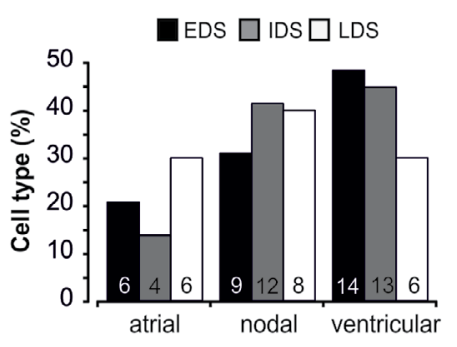

D Iso

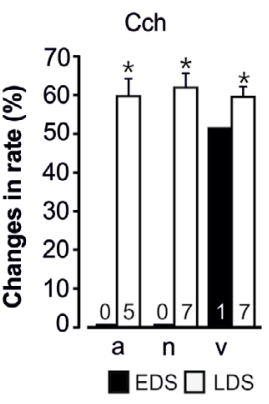

Fig. 2. Electrophysiological functionality of miPSC-derived CMs. (A) Representative AP recordings from spontaneously beating LDS miPS-CMs. All developmental stages revealed the different cardiac subtypes: Embryonic atrial (a)-, nodal (n)-, and ventricular (v)-like CMs. (B) The classification of different cardiac cell types was based on the morphology of the APs and AP parameters (MDP, APA, $V_{\text {max }}$ and APD) as described in the result section. (C) Left: Representative traces of spontaneous APs recorded in LDS CMs in the absence and presence of $1 \mu \mathrm{M}$ isoproterenol (Iso) or $1 \mu \mathrm{M}$ carbachol (Cch); Right: Fractions of CMs responding to drug application. (D) Statistics of the chronotropic effect of drugs (1 1 M Iso, $1 \mu \mathrm{M}$ Cch) on different cardiac subtypes generated from miPSCs after UTF1 selection. Data are expressed as the mean $\pm \mathrm{SEM},{ }^{*} \mathrm{P}<0.05 v s$. control values; dotted lines indicate the potentials at $0 \mathrm{mV}$.

Iso $(1 \mu \mathrm{M})$ and Cch $(1 \mu \mathrm{M})$ during the recording of APs induced a significant positive (Fig. 2C, above) and negative (Fig. 2C, below) chronotropic effect, with respect to the stage of differentiation and the cardiac subtype as shown in Figure 2D and Table $2(\mathrm{P}<0.05)$. However, some EDS and LDS CMs did not respond to these drugs (drug-responding cell fraction shown in Fig. 2C, right panel, Table 2). These cells were, therefore, considered as "not responding" and excluded from the statistical analysis. The atrial-like CMs at EDS responded to neither Iso nor Cch (Fig. 2C, right panel). 17\% of the EDS nodal cells responded to Iso, while none of them showed any changes in the beating frequency after application of Cch. Of the early ventricular cells $25 \%$ responded to Iso, and $13 \%$ to Cch. Thus, from all measured EDS CMs only very few showed a reaction after drug application, however, even in these cells the frequency 
Table 2. Drug effects on beating frequencies (bpm) induced by either $1 \mu \mathrm{M}$ Iso or $1 \mu \mathrm{M}$ Cch compared to control medium (ctrl). "0" indicates that none of the measured CMs responded to the respective drug. Numbers in brackets indicate the amount of CMs showing a change of the control value of at least $20 \%$ as reaction to the drug out of all measured cells. Data are expressed as the mean $\pm \mathrm{SEM},{ }^{*} \mathrm{P}<0.05$ vs. ctrl

\begin{tabular}{|c|c|c|c|c|c|c|c|c|c|c|c|c|}
\hline & \multicolumn{4}{|c|}{ a } & \multicolumn{4}{|c|}{$\mathrm{n}$} & \multicolumn{4}{|c|}{$\mathrm{V}$} \\
\hline & ctrl & Iso & ctrl & Cch & ctrl & Iso & ctrl & Cch & ctrl & Iso & ctrl & Cch \\
\hline EDS & 0 & 0 & 0 & 0 & $\begin{array}{c}922 \pm 164 \\
\text { (2) }\end{array}$ & $\begin{array}{c}457 \pm 248 \\
\text { (2) }\end{array}$ & 0 & 0 & $\begin{array}{c}245 \pm 60 \\
(2)\end{array}$ & $\begin{array}{c}406 \pm 93 \\
(2)\end{array}$ & $\begin{array}{r}302 \\
(1)\end{array}$ & $\begin{array}{l}147 \\
(1)\end{array}$ \\
\hline LDS & $\begin{array}{c}344 \pm 43 \\
(11)\end{array}$ & $\begin{array}{c}576 \pm 70 \\
(11)^{*}\end{array}$ & $\begin{array}{c}422 \pm 76 \\
(5)\end{array}$ & $\begin{array}{c}179 \pm 46 \\
(5)\end{array}$ & $\begin{array}{c}262 \pm 32 \\
(7)\end{array}$ & $\begin{array}{c}469 \pm 55 \\
(7)^{*}\end{array}$ & $\begin{array}{c}435 \pm 50 \\
(7) \\
\end{array}$ & $\begin{array}{c}163 \pm 24 \\
(7)^{*}\end{array}$ & $\begin{array}{c}266 \pm 50 \\
(6)\end{array}$ & $\begin{array}{c}622 \pm 38 \\
(6)^{*}\end{array}$ & $\begin{array}{c}461 \pm 77 \\
(7)\end{array}$ & $\begin{array}{c}184 \pm 33 \\
(7)^{*}\end{array}$ \\
\hline
\end{tabular}

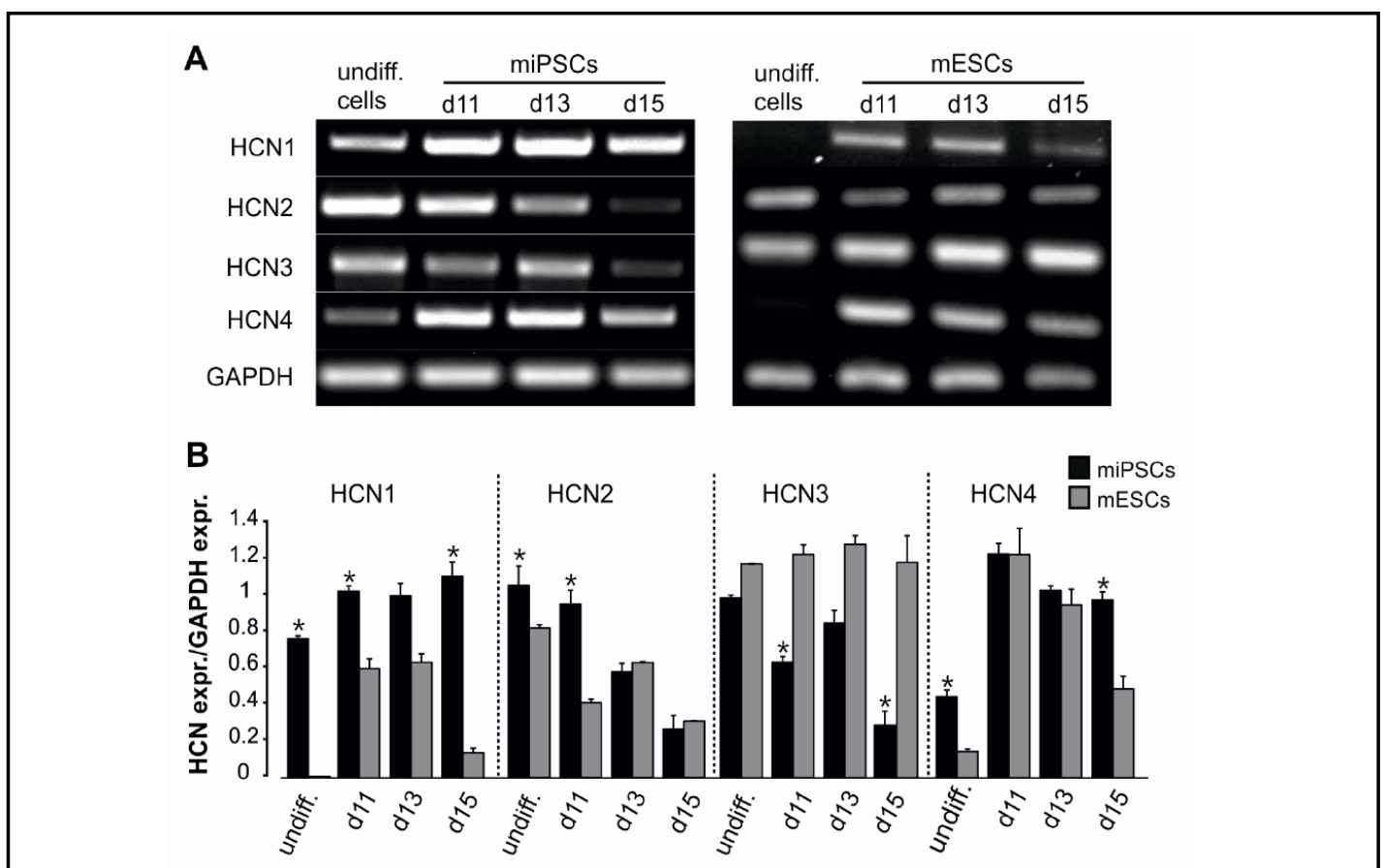

Fig. 3. HCN gene expression in miPSC- compared with mESC-derived CMs (mean values of 3 differentiation approaches for miPSCs and mESCs, respectively). (A) RT-PCR analysis demonstrating expression of indicated genes in undifferentiated (undiff.) cells and microdissected spontaneously contracting areas of mESC-EBs and miPS-EBs at day 11, 13, and 15 of differentiation (mESCs, miPSCs, d11, d13, d15). (B) Relative expression level of HCN mRNA in miPSC- compared with mESC-derived CMs. Expression levels were normalized to the band intensity of each gene relative to the band intensity of GAPDH. Data are expressed as the mean \pm SEM. $* \mathrm{P}<0.05$ vs. mES-CMs.

did not alter significantly (Table 2$)$. In LDS, most measured CMs ( $\sim 70$ to $80 \%)$ showed a significant drug-induced change in the beating rates of. all three cell types $(\mathrm{P}<0.05)$ (Fig. $2 \mathrm{D}$, Table 2). The most obvious change could be determined in ventricular-like CMs after application of Iso, which induced a frequency increase of $134 \pm 25 \%$ (from $266 \pm 50 \mathrm{bpm}$ to $622 \pm 38 \mathrm{bpm}$ ) $(\mathrm{P}<0.05)$ in LDS. In atrial CMs the change accounted for $68 \pm 5 \%$ (from $344 \pm 43$ bpm to $576 \pm 70 \mathrm{bpm}$ ), in nodal CMs for $79 \pm 8 \%$ (form $262 \pm 32 \mathrm{bpm}$ to $469 \pm 55 \mathrm{bpm}$ ). The application of Cch resulted in a decrease of the beating frequency of about $60 \%$ in all LDS CMs. The results clearly show that CMs generated from miPSCs after UTF1 transfection are functionally intact and that these cells display typical features of the hormonal regulation of chronotropy (conduction velocity) in the late differentiation stages.

\section{HCN Gene Expression in miPS-CMs}

To evaluate the expression levels of cardiac HCN channel isoforms in miPS-CMs, RTPCR was performed. Figure 3A shows the transcription level of HCN genes (HCN1-4) in undifferentiated miPSCs and mESCs and in autonomously, spontaneously contracting 


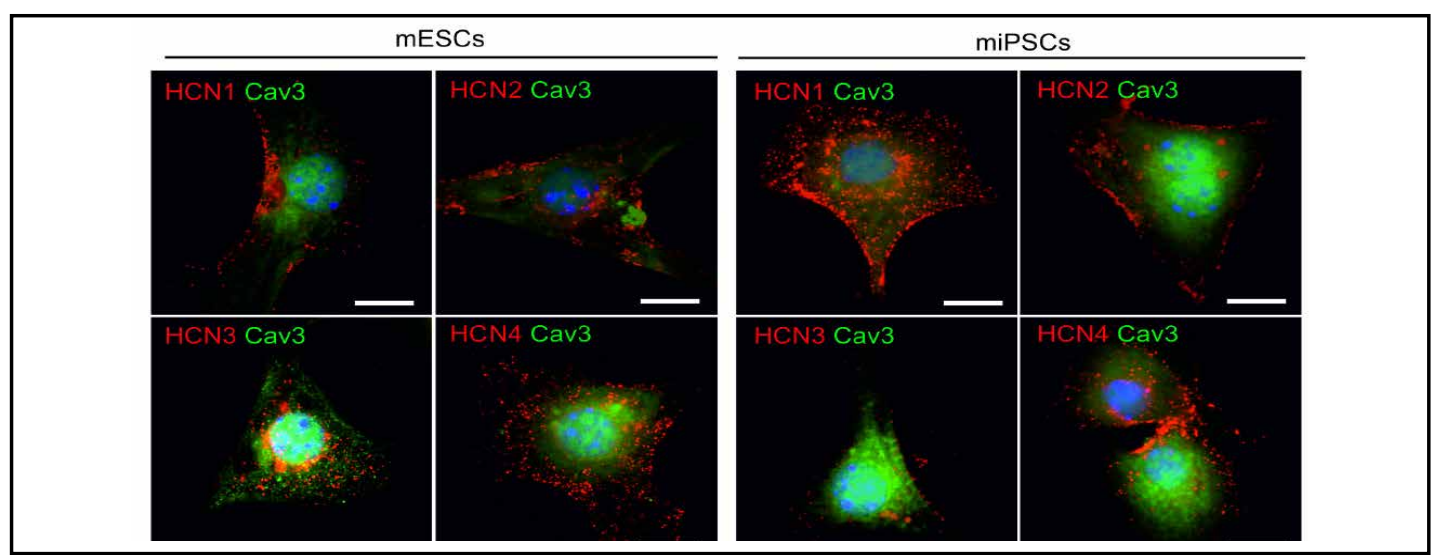

Fig. 4. Expression of HCN isoforms in CMs differentiated from mESCs (left) and miPSCs (right). Confocal images of single CMs labeled with specific anti-HCN antibodies (red) and caveolin (green) at day 15 of differentiation. Nuclei were stained with Hoechst 33432 (scale bar: $10 \mu \mathrm{m}$ ).

EBs at day 11, day 13 and day 15 of differentiation. The analysis of the expression levels (Fig. 3B) revealed that all HCN subunits were expressed in undifferentiated miPSCs. The expression levels of HCN1 during day 11 and day 15 of differentiation did not differ much from each other, compared to HCN2 and HCN3, which suggest considerable decreases in beating clusters of EBs at day 15 of differentiation, indicating changes in the expression levels of HCN genes during the differentiation process to CMs. Interestingly, only few undifferentiated mESCs expressed HCN1 and HCN4 gene transcripts at detectable levels, in contrast to undifferentiated miPSCs. Moreover, the expression level of HCN1 appears to be very low in differentiated mESCs from EBs harvested on day 15, although this transcript showed a stronger expression in these cells at days 11 and 13 of differentiation. In miPSCs, HCN4 remained relatively constant throughout differentiation, showing a relatively high expression level, while our experiments suggest a lower expression level of HCN4 in mESCs of LDS compared with EDS (Fig. 3B).

To determine whether the results from RT-PCR analyses are reflected on protein level, we performed immunocytochemistry on CMs generated from miPSCs at day 15 of differentiation using subtype-specific anti-HCN antibodies (Fig. 4) in comparison to mESC-derived CMs. We examined the expression of various HCN isoforms on protein level of single cardiac cells, which we co-stained with caveolin 3 as a muscular/cardiac differentiation marker to confirm myocyte identity. In agreement with the RT-PCR results, we found that LDS CMs from both mESCs and miPSCs expressed all HCN subunits (red), which were distributed over the cell membrane of caveolin 3-expressing cells (green). The stainings suggest, that HCN1 was relatively highly expressed in miPSC- compared with mESC-derived LDS CMs, whereas other HCN isoforms (especially HCN3) were expressed at lower levels in miPSCs compared with mESCs, confirming the PCR data. In all four HCN/caveolin co-stainings, we identified cells positive for caveolin, but negative for HCN, suggesting that not all CMs express HCNproteins (Fig. 4, HCN-neg.).

\section{Identification of functional If current}

Because miPSC-derived CMs express HCN (especially HCN4 and HCN1 isoforms) typically found in the SAN, we also analyzed their APs and $I_{\mathrm{f}}$ currents using the patch-clamp technique. APs and $I_{\mathrm{f}}$ currents were recorded from the same cell by switching from current- to voltage-clamping as previously described [4]. None of the measured undifferentiated miPSCs $(\mathrm{n}=50)$ showed any $I_{\mathrm{f}}$ current (Fig. $5 \mathrm{~A}$, left panel). The voltage-clamp protocol used and the typical representative current traces recorded in undifferentiated cells and spontaneously beating CMs at EDS and LDS are depicted in Figure 5A, left panel. The percentage of miPSCderived CMs expressing $I_{\mathrm{f}}$ is shown in Figure 5A, right panel. The $I_{\mathrm{f}}$ current was detected in $71 \%, 80 \%$, and $76 \%$ of measured CMs at EDS, IDS and LDS, respectively. The voltage- 


\section{A}

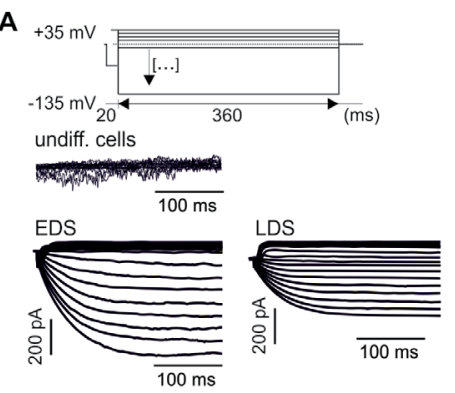

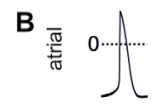
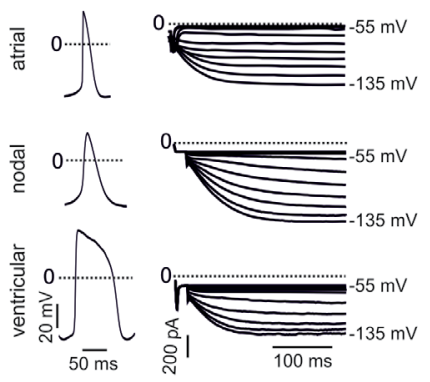

D

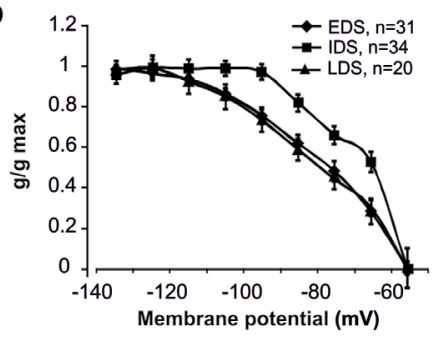

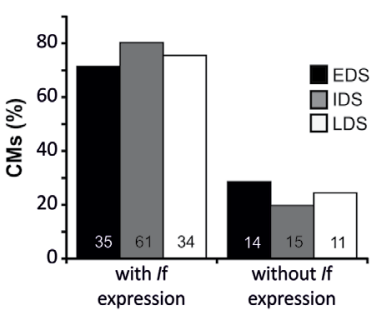
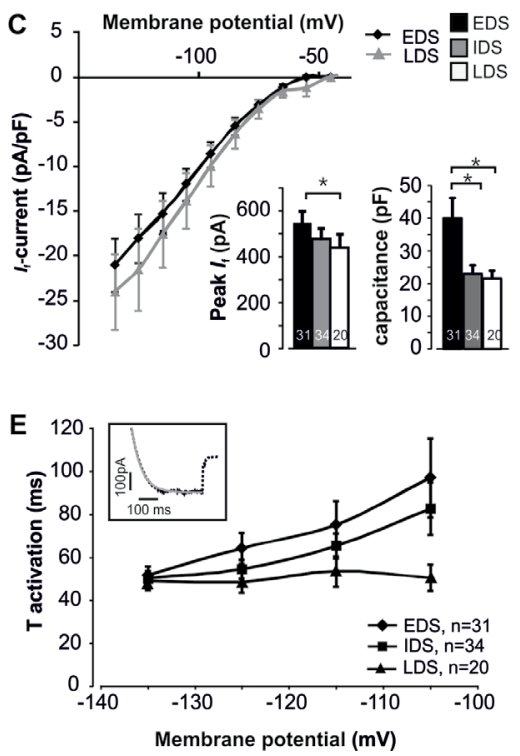

Fig. 5. Changes in $I_{\mathrm{f}}$ currents in miPS-CMs during differentiation. (A) Left: Representative $I_{\mathrm{f}}$ current traces of undifferentiated miPSCs and spontaneously beating CMs derived from miPSCs at indicated stages of differentiation (EDS or LDS). The pulse protocol shown above the traces was used. Hyperpolarizing steps from $-135 \mathrm{mV}$ to $+35 \mathrm{mV}$ in increments of $10 \mathrm{mV}$ (holding potential of $-55 \mathrm{mV}$ ) were applied to determine the conductance-voltage relationships; Right: The numbers of CMs showing an $I_{\mathrm{f}}$ current and not showing any $I_{\mathrm{f}}$ current were determined in all three developmental stages. (B) Representative traces of APs and $I_{\mathrm{f}}$ currents recorded simultaneously in LDS CMs. Spontaneous AP pattern of an miPS-CM was recorded with current-clamp, the $I_{\mathrm{f}}$ current was subsequently recorded in the same cell with voltage-clamp technique. (C) Current-voltage relationship $(I-V)$ of the $I_{\mathrm{f}}$ current from CMs of EDS and LDS with application of voltages from -135 to $-45 \mathrm{mV}$. The inserts show the peak $I_{\mathrm{f}}$ currents and the cell capacitances in EDS, IDS and LDS; (D) Normalized conductance $\left(\mathrm{g} / \mathrm{g}_{\max }\right)$-voltage curves calculated from the I-V relations, specific conductance of $I_{\mathrm{f}}$ was determined for each cell according to the equation $\mathrm{g}=\mathrm{I} /\left(\mathrm{V}_{\mathrm{m}}-\mathrm{V}_{\text {rev }}\right)$ at various differentiation times. (E) Voltage dependence of activation time constant at different stages of differentiation. The insert shows a representative trace of the maximum $I_{\mathrm{f}}$ current measured at $-135 \mathrm{mV}$. Time courses of the current activation were fitted by single exponentials. Data are expressed as the mean $\pm \mathrm{SEM},{ }^{*} \mathrm{P}<0.05$; dotted lines indicate the potentials at $0 \mathrm{mV}$.

dependent activity of $I_{\mathrm{f}}$ was noticed it in atrial-, nodal-, and ventricular-like cells. This could be verified by simultaneously recording of APs without the addition of any drug in the first step to determine the cell type (Fig. 5B, left panel) and, after switching from current- to voltage-clamp mode, measuring the $I_{\mathrm{f}}$ currents (Fig. 5B, right panel). The current amplitude of $I_{\mathrm{f}}$ determined as the difference between the peak inward current and the current in the initial phase of the pulse step, decreased significantly $(\mathrm{P}<0.05)$ in miPSC-derived CMs from EDS (547 $\pm 50 \mathrm{pA}, \mathrm{n}=31)$ to LDS $(462 \pm 50 \mathrm{pA}, \mathrm{n}=20)$ (Fig. 5C, left insert). Although the maximal $I_{\mathrm{f}}$ currents in EDS exceed those in LDS, a normalization of the current to the significantly 
Fig. 6. Different representative beating patterns in late stage CMs. (A) fast and regular action potentials, (B) slow and regular action potentials, (C) fast and irregular action potentials, (D) slow and irregular action potentials. CMs of EDS show the same beating patterns with a different distribution; dotted lines indicate the potentials at $0 \mathrm{mV}$.

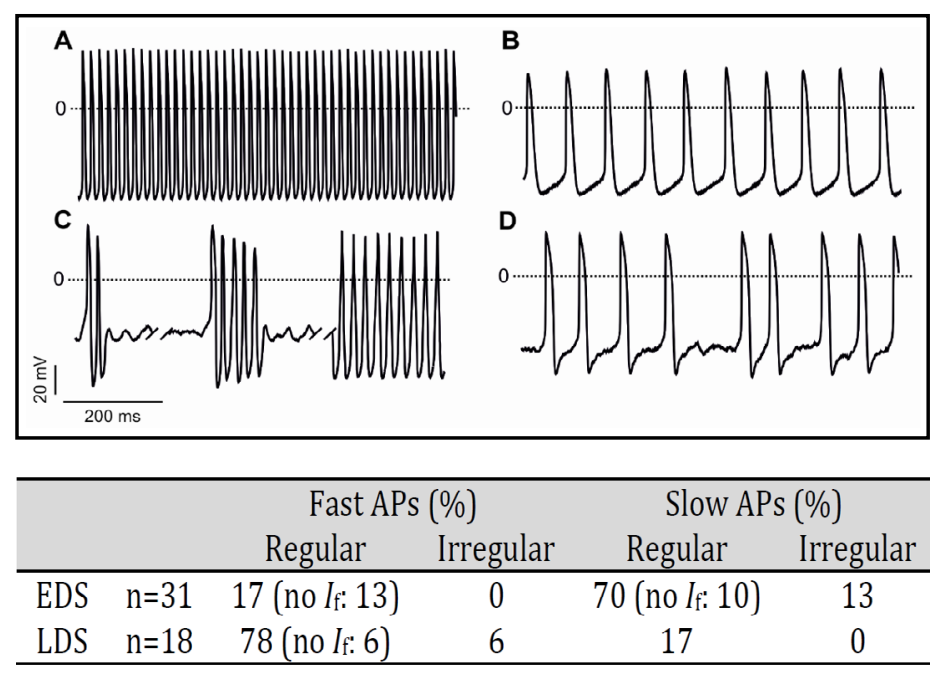

Table 3. Ratios of different beating pattern in CMs from EDS and LDS. Values in brackets show the portion of measured CMs without $I_{\mathrm{f}}$ expression (no $I_{\mathrm{f}}$ )

differing cell capacitance (capacity values are shown in Fig. 5C, right insert) revealed larger $I_{\mathrm{f}}$ current densities in LDS CMs compared with those at EDS (Fig. 5C). The $I-V$ curves show that the $I_{\mathrm{f}}$ current activation range extended from approximately -50 to $-135 \mathrm{mV}$. We measured the current density $(I-V)$ relationships at the end of each voltage step and normalized them to the maximal current density to generate a conductance relation (Fig. 5D). The membrane conductance $g$ was calculated by $g=I /\left(V-V_{\text {rev }}\right)$ and normalized to the maximal conductance $\mathrm{g}_{\text {max }}$. The voltage $V_{\text {rev }}$ of the $I_{\mathrm{f}}$ current in each differentiation stage is defined as the voltage at which the current reverses from negative into positive values. It was determined from the $I-V$ relationships shown in Figure $5 \mathrm{C}$ and amounted to $-55 \mathrm{mV},-55 \mathrm{mV}$, and $-45 \mathrm{mV}$ in EDS, IDS, and LDS cells, respectively, which is similar to the MDP values recorded from the APs of spontaneously beating CMs at the same stage of differentiation (Table 1). However, a precise threshold activation of $I_{\mathrm{f}}$ could not be determined because each cell operates safely within a normal voltage range, depending on the stage of maturation, and may become unstable if charged to higher voltages, as previously described [16]. A comparison of the activation kinetics during differentiation was performed by mono-exponential fittings in CMs at EDS, IDS, and LDS. With more negative voltage pulses the activation of the measured current became progressively faster. Figure $5 \mathrm{E}$ demonstrates the time constants $(\tau)$ of current activation determined by monoexponential fitting of individual current traces recorded in CMs of EDS, IDS, and LDS at -135 to $-105 \mathrm{mV}$ (a voltage window at which maximal HCN activation occurs). Mean $\tau_{\text {act }}$ values were plotted as a function of the membrane potential. The insert represents an example of a fit in an LDS CM, measured at $-135 \mathrm{mV}$, showing a time constant of $49 \mathrm{~ms}$. The activation time constant (mono-exponential fitting) of CMs at EDS ( $\tau_{\mathrm{EDS}}$ ), IDS ( $\left.\tau_{\mathrm{IDS}}\right)$, and LDS ( $\left.\tau_{\mathrm{LDS}}\right)$ varied between $97 \pm 18 \mathrm{~ms}$ (EDS), 83 $\pm 12 \mathrm{~ms}$ (IDS), and $51 \pm 6 \mathrm{~ms}$ (LDS) at $-105 \mathrm{mV}$ to $52 \pm 4 \mathrm{~ms}$ (EDS), $50 \pm 3 \mathrm{~ms}$ (IDS), and $49 \pm 4 \mathrm{~ms}$ (LDS) at $-135 \mathrm{mV}$, respectively. We could not detect $I_{\mathrm{f}}$ currents in all spontaneously beating CMs showing APs. Of the EDS CMs, the main portion (70\%) of the measured cells showed slow and regular APs. From these $70 \%, 10 \%$ did not display $I_{\mathrm{f}}$ currents (Fig. 6 and Table 3). Slow and irregular APs could be observed in 13\% of EDS CMs. $17 \%$ displayed fast and regular APs, $13 \%$ of these did not show any $I_{\mathrm{f}}$ currents. None of the early CMs displayed fast and irregular APs. In LDS, the main portion of the cells, $78 \%$, showed fast and regular beating, $6 \%$ of these did not show any $I_{\mathrm{f}}$ currents. Minor portions showed fast and irregular APs (6\%), and slow and regular APs (17\%). Slow and irregular APs were not measured at all in LDS CMs (Table 3).

Pharmacological properties of HCN channels in miPS-CMS

To evaluate the functionality of the HCN channels and the contribution of $I_{\mathrm{f}}$ current to the automaticity of miPS-CMs, we examined the effect of the two $I_{\mathrm{f}}$ inhibitors, cesium chloride 


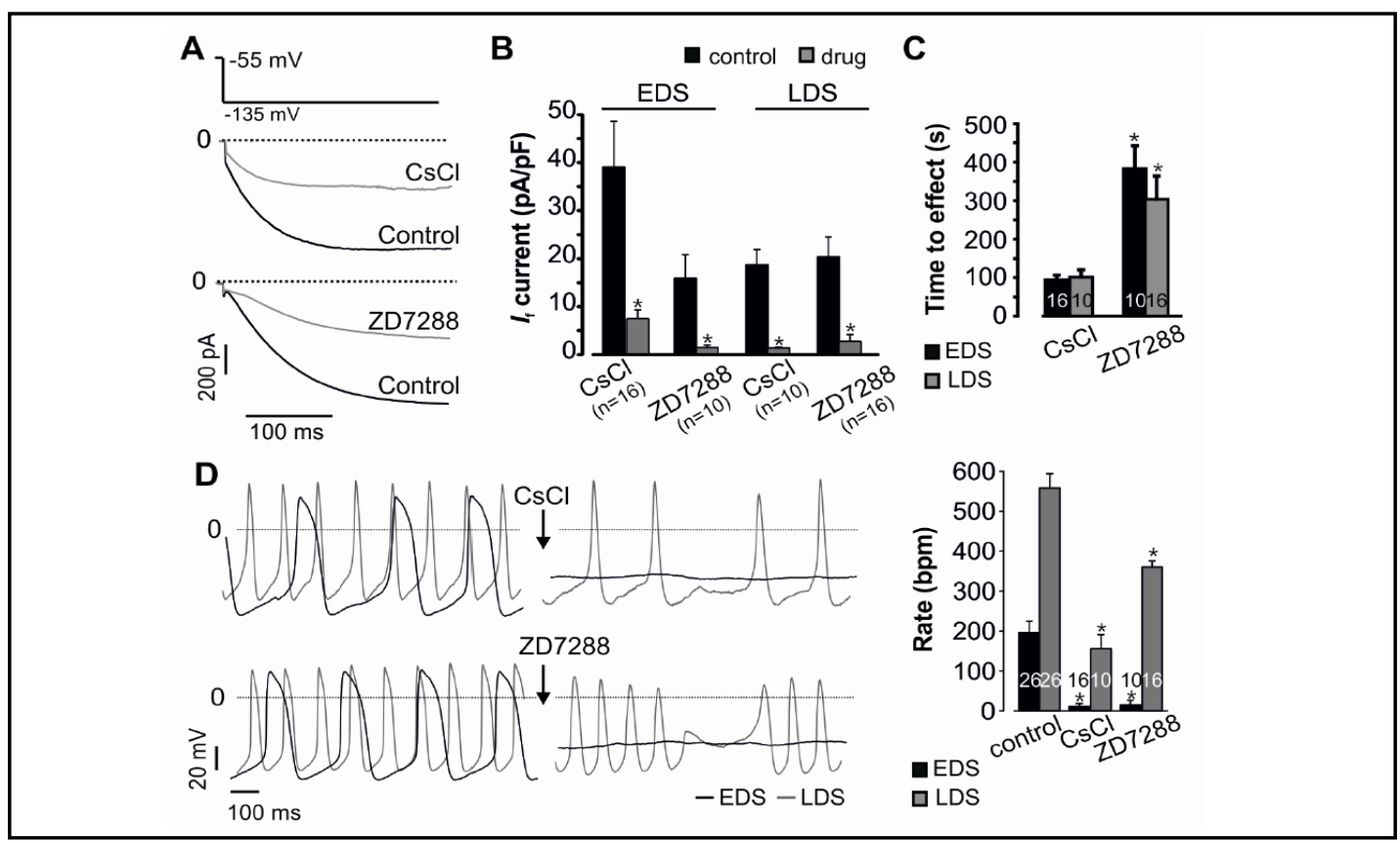

Fig. 7. Pharmacological characterization of $I_{\mathrm{f}}$ in miPS-CMs at different stages of differentiation. (A) Pulse protocol and representative $I_{\mathrm{f}}$ traces before (control) and during application of unspecific (CsCl) and specific (ZD7288) $I_{\mathrm{f}}$ blockers. (B) Partial inhibition of maximal $I_{\mathrm{f}}$ current density by CsCl and ZD7288. (C) The time it took to achieve the maximal blocking effect in EDS and LDS is presented; (D) Left: Representative traces showing the effect of $\mathrm{CsCl}$ and ZD7288 on the beating frequency of isolated CMs at LDS; Right: Note the decrease of $\mathrm{CM}$ beating frequency in the presence of the indicated drug. Data are expressed as the mean $\pm \mathrm{SEM}$, $* \mathrm{P}<0.05$; dotted lines indicate the potentials at $0 \mathrm{mV}$.

(CsCl) and ZENECA ZD7288 (4-(N-ethyl-N-phenylamino)-1,2-dimethyl-6-(methylamino) pyrimidinium chloride) (ZD7288), non-specific and specific HCN blockers, respectively. In Figure 7A, representative $I_{\mathrm{f}}$ current traces recorded in single LDS CMs in control solution and in the presence of $\mathrm{CsCl}(10 \mathrm{mM}$, as previously used [27]) and ZD7288 (10 $\mu \mathrm{M}$, as previously used [24]) are shown. The extracellular application of both drugs to miPS-CMs strongly inhibited the current amplitude and density of inward $I_{\mathrm{f}}$ at $-135 \mathrm{mV}$ at EDS, IDS, and LDS. Application of CsCl significantly blocked the $I_{\mathrm{f}}$ density by $81 \%$ (from $39.1 \pm 9.5 \mathrm{pA}$ / $\mathrm{pF}$ to $7.5 \pm 1.8 \mathrm{pA} / \mathrm{pF}$ ) at EDS and $91 \%$ (from $18.7 \pm 3.2 \mathrm{pA} / \mathrm{pF}$ to $1.4 \pm 0.2 \mathrm{pA} / \mathrm{pF}$ ) at LDS, respectively, whereas ZD7288 significantly reduced the $I_{\mathrm{f}}$ density by up to $93 \%$ (from 15.9 $\pm 4.9 \mathrm{pA} / \mathrm{pF}$ to $1.5 \pm 0.5 \mathrm{pA} / \mathrm{pF}$ ) at EDS and $86 \%$ (from $20.4 \pm 4.1 \mathrm{pA} / \mathrm{pF}$ to $2.8 \pm 1.4 \mathrm{pA} / \mathrm{pF}$ ) at LDS, respectively $(\mathrm{P}<0.05)$ (Fig. 7B). The blocking effect of $\mathrm{CsCl}$ set in significantly faster (EDS: $95 \pm 12$ s, LDS: $101 \pm 19 \mathrm{~s}$ ) compared to this of ZD7288 (EDS: $384 \pm 59$ s, LDS: $304 \pm 60 \mathrm{~s}$ ) $(\mathrm{P}<0.05)$ (Fig. 7C). The inhibition of $I_{\mathrm{f}}$ was accompanied by a slowing of the spontaneous AP firing rate and a prolonged AP depolarization phase (Fig. 7D). After applying the respective drug, the beating frequency in EDS CMs decreased significantly from $196 \pm 29$ beats $/ \mathrm{min}$ (bpm) to $10 \pm 8$ (with $\mathrm{CsCl}$ ) and $15 \pm 11 \mathrm{bpm}$ (with ZD7288). In LDS CMs the beating frequency decreased significantly from $558 \pm 36 \mathrm{bpm}$ to $156 \pm 36 \mathrm{bpm}$ and $361 \pm 15 \mathrm{bpm}(\mathrm{P}<0.05)$ in the presence of $\mathrm{CsCl}$ and ZD7288, respectively (Fig. 7D, right panel). Approximately 2-3 min after drug application, $81 \%$, and $38 \%$ of CMs at EDS and LDS, respectively, stopped beating.

Taken together, miPSCs selected by the UTF1 vector provide an interesting tool for applications in pharmacology and event toxicology. Moreover, it suggests that these cells were committed to mostly pacemaking nodal CMs expressing $I_{\mathrm{f}}$ channels, thus confirming not only the contribution of $I_{\mathrm{f}}$ channels to the generation of spontaneous activity but also their function in controlling the beating rate of CMs. 


\section{Discussion}

The present study shows the capacity of UTF1-selected miPSCs to differentiate into CMs with less variability in terms of beating activity for an extended period compared to mESCs; the fraction of spontaneous contractile EBs was higher in miPSC-EBs (Fig. 1). CMs derived from miPSCs showed APs of all three cardiomyocyte subtypes, functional $\beta$-adrenergic and muscarinic signaling (Fig. 2), the expression of heart-specific HCN isoforms 1 and 4 (Fig. 3 and Fig. 4), and functional $I_{\mathrm{f}}$ currents at EDS, IDS and LDS (Fig. 5).

In our study, we demonstrate the molecular composition and functional properties of HCN channels in CMs derived from UTF1-selected miPSCs during differentiation through EB formation. Using molecular analysis and patch-clamp recordings, we found some novel and important pieces of information regarding HCN isoforms, in particular HCN1 and HCN4, in mammalian CMs. RT-PCR analyses revealed the mRNA expression of all HCN subunits in undifferentiated cells and in CMs of day 11,13, and 15 (Fig. 3). Both, RT-PCR results and immunostainings of the HCN isoforms indicate a prevalent expression of HCN1 and HCN4 isoforms in miPS-CMs in a differentiation-stage-dependent manner, which appears to be higher in miPS-CMs as compared to mESC-CMs (Fig. 3 and 4). HCN2 and HCN3 expression was found to be already present in undifferentiated mESCs and in miPSCs. HCN2 mRNA expression was observed to decrease over the course of miPSC and mESC differentiation. The levels of HCN3 in mESCs appear higher compared to miPSCs. They also show a decreasing tendency in miPSCs. These results are in line with previous findings in mESCs, where HCN2 and HCN3 have been shown to be present not only in early but also in late stages of differentiation [28]. The differences in HCN-protein expression between mESC and miPSCderived CMs might be due to different fractions of cardiomyocyte subtypes and changing expression levels of the isoforms during development. In mature hearts, HCN1, HCN2, and HCN4 isoforms have been shown to be expressed [29], while very low levels of HCN3 have been detected. Only HCN4 has been shown to be the specific marker of pacemaker cells; HCN4 is expressed in up to $80 \%$ of the SAN and is considered to be crucial for the initiation and control of beating activity of these cells [7]. However, previous studies also revealed that the HCN1, HCN2, and HCN3 isoforms are variably distributed in the SAN as well as in other cardiac regions and excitable tissues [28, 30,31]. Additionally, there is a high variation of HCN isoform expression according to species. For example, HCN4 is the dominant isoform in adult human, rabbit, and mouse SANs, whereas in the adult rat SAN, HCN2 is the predominant HCN isoform [11, 32-35]. In general, HCN channels play an important role in cardiac pacemaker activity and thus for the initiation of contractility. Indeed, HCN2-knockout mice show a reduced $I_{\mathrm{f}}$ current with relative sinus arrhythmia at rest [36], whereas HCN4-knockout mice die during embryogenesis owing to heart rhythm disturbances [33].

Immunostaining furthermore revealed a co-localization of caveolin 3 with all HCN subunits in the late differentiation stage of mES- and miPSC-derived CMs at single cell level (Fig. 4). Caveolin 3 is a structural protein of muscular/cardiac caveolae that regulates channel activation properties and responsiveness to adrenergic modulation [36, 37]. Predominantly, expressed in SAN cells, it has been shown to colocalize and interact with HCN4 in isolated myocytes. This interaction seems to be critically important for HCN channel function and modulation [36]. It has also been shown, that a developmental change in HCN-caveolin 3 association exists in CMs $[37,38]$. Due to the influence of $I_{\mathrm{f}}$ on the diastolic membrane potential, developmental changes in channel compartmentalization and the association to caveolin 3 may play an important role for the cell physiology and the progression towards the adult cardiac phenotype. Our results support that both the acquisition of nodal-like phenotype typical of SAN cells and a precise sarcolemmal organization of HCN channels and caveolin 3 proteins occur in a development-dependent manner. As it has been demonstrated in mESCs, a colocalization of HCN1 and caveolin 3 could also be possible in miPSC-derived CMs [36]. Indeed, HCN1 and HCN4 are the HCN isoforms that are most highly expressed in SAN cells of different species [32, 39, 40]. HCN staining reveals a ubiquitous distribution of HCN channels in the cell membrane of CMs. It has been shown that subunit heteromerization 
and glycosylation of the HCN protein is necessary for proper trafficking and surface expression [41].

The growing percentage of drug-responsive miPSC-derived CMs from early to late stages observed here shows an increasing maturation level during differentiation (Fig. 2).Despite the presence of all HCN subtype transcripts in undifferentiated miPSCs (Fig. 3), we were not able to record $I_{\mathrm{f}}$ currents in whole-cell patch-clamp experiments (Fig. 5); this could be attributed to the lack of functional channels, immaturity or low current flow in undifferentiated cell membranes, as previously suggested [31]. However, we recorded $I_{\mathrm{f}}$ and observed an increase in $I_{\mathrm{f}}$ current densities in most CMs in a development-dependent fashion (Fig. 5). This has been shown before by others in CMs derived from human ESCs [29, 37], suggesting that this developmental progress might be similar in murine and human CMs. In fact, it seems that in ESC-derived CMs of EDS, the primitive pacemaker potentials are generated by $I_{\mathrm{CaL}}$ and $I_{\mathrm{K}, \mathrm{to}}$ but not by $I_{\mathrm{f}}$ [42]. The increase in $I_{\mathrm{f}}$ current was correlated with a decrease in the expression of HCN2 and HCN3, whereas HCN1 and HCN4 expression remained relatively unchanged in the later stages of differentiation (Fig. 3). The $I_{\mathrm{f}}$ current, which is the mixed inward current carried by $\mathrm{Na}^{+}$and $\mathrm{K}^{+}$ions, is characterized by (i) channel activation via membrane hyperpolarization, (ii) channel activation via direct interaction with cAMP and (iii) a specific pharmacological profile [7]. As previously reported [31], we also found CMs harvested from beating EBs at the late stage of differentiation (day 15), expressing either a rapid or slow $I_{\mathrm{f}}$ current activation (Fig. 5). The occurrence of a fast kinetic activation of $I_{\mathrm{f}}$ has been postulated by several authors in different CM-species $[31,43]$. However, it is not a fully established concept and has to be further investigated. While the slow activation is attributed to cations passing the channel pore, the nature of the fast activation is not yet clear. We observed that in some CMs, the $I_{\mathrm{f}}$ current could not be recorded despite the spontaneous beating activity determined by AP measurements. These cells, mostly recorded in the early stage of differentiation, show more immature properties; indeed they beat regularly but more slowly than LDS cells (Fig. 6). In fact, the efflux of $\mathrm{Ca}^{2+}$ from intracellular storage via Inositoltriphosphate (IP3), the sarcoplasmic/endoplasmic reticulum calcium ATPase (SERCA) or the ryanodine receptor (RyR) may contribute to the beating activity of CMs that do not possess functional and measurable $I_{\mathrm{f}}$ currents $[4,44]$ because a block of L-type $\mathrm{Ca}^{2+}$ channels has been shown to abolish the beating activity in iPS-CMs $[2,22]$. Most CMs recorded in the late stage of differentiation possess detectable $I_{\mathrm{f}}$ currents and beat faster with regular rhythm. The presence of $I_{\mathrm{f}}$ currents in most CMs at the late stage compared with the early stage of differentiation shows an ongoing maturation and the expression of HCN and others ion channels, which has been suggested to contribute to spontaneous activity in neonatal and adult CMs $[4,45,46]$. The leftward shift of half maximal activation potential of $I_{\mathrm{f}}$ current may be explained by modifications in channel composition during the developmental process. Moreover, different factors are likely to contribute to this modification, including the interaction with caveolin3 that different data present in literature report to increase during cardiomyocyte maturation [47]. However, further investigations are needed to confirm this statement. The changes in the $I_{\mathrm{f}}$ current may also reflect variations in the intracellular cAMP level, as cAMP is considered to be a second messenger in $I_{\mathrm{f}}$ current modulation [6]. In agreement with previous studies in different cell types and species as well as cells lines [48-52], we found that the $I_{\mathrm{f}}$ blockers $\mathrm{CsCl}$ and ZD7288 dramatically reduced the density of the $I_{\mathrm{f}}$ current and decreased the AP frequency of CMs derived from UTF1-selected miPSCs in a development-dependent manner, confirming that $I_{\mathrm{f}}$ is specifically involved in the initiation and maintenance of spontaneous activity and the rate control of isolated CMs (Fig.7). As evidence indicates, $\beta$-adrenergic receptor (AR) stimulation increases AP frequency and $I_{\mathrm{f}}$ by shifting the activation curve of the current to the right, as opposed to the left shift of the $I_{\mathrm{f}}$ current activation curve induced by muscarinic receptor stimulation via the inhibition of adenylate-cyclase and cAMP [6].

Because the investigated UTF1-selected miPSCs show similar and even improved properties compared with control mESCs, these cells could serve as a model to determine drug influences on the ion channels or on cell metabolism, or even for future transplantation 
purposes. Especially the large ratio of pacemaker-like cells might be an advantage for therapeutical applications that acquire a controlled composition of cell types. To represent functional cell populations in a mature in vivo-like cardiac tissue, certain homogeneity of the cells is important. Furthermore, the high degree of spontaneously contracting areas inside the miPSC-derived EBs and the constancy of this high amount of beating cells during development might prove them to be an interesting cell source for pre-clinical drug development projects or the optimization of biological pacemakers in heart therapy.

\section{Abbreviations}

MDP (maximum diastolic potential); APA (action potential amplitude); bpm (beats per $\min$ ); $\mathrm{V}_{\max }$ (maximal velocity of depolarization); APD30/60/90 (action potential duration at 30,60 and $90 \%$ of repolarization); ${ }^{*}(\mathrm{P}<0.05$, significant difference between the relevant parameter in the same cell type $(a, n, v)$ in early and late differentiation stages, respectively).

\section{Acknowledgments}

We thank Rudolf Jaenisch and Alexander Meissner (Whitehead Institute of Technology, MA, USA) for providing us with TiB7-4 iPSCs. We thank Susan Rohani, Annette Köster and Manoj Gupta for their excellent technical assistance. This study was partially supported by EU FP7 project STEMCAM.

\section{Disclosure Statement}

No competing financial interests exist.

\section{References}

$>1$ Heng BC, Haider H, Sim EK, Cao T, Ng SC: Strategies for directing the differentiation of stem cells into the cardiomyogenic lineage in vitro. Cardiovasc Res 2004;62:34-42.

2 Pfannkuche K, Liang H, Hannes T, Xi J, Fatima A, Nguemo F, Matzkies M, Wernig M, Jaenisch R, Pillekamp F, Halbach M, Schunkert H, Saric T, Hescheler J, Reppel M: Cardiac myocytes derived from murine reprogrammed fibroblasts: intact hormonal regulation, cardiac ion channel expression and development of contractility. Cell Physiol Biochem 2009;24:73-86.

3 Mauritz C, Schwanke K, Reppel M, Neef S, Katsirntaki K, Maier LS, Nguemo F, Menke S, Haustein M, Hescheler J, Hasenfuss G, Martin U: Generation of functional murine cardiac myocytes from induced pluripotent stem cells. Circulation 2008;118:507-517.

-4 Qu Y, Whitaker GM, Hove-Madsen L, Tibbits GF, Accili EA: Hyperpolarization-activated cyclic nucleotidemodulated 'HCN' channels confer regular and faster rhythmicity to beating mouse embryonic stem cells. J Physiol 2008;586:701-716.

5 Yu H, Chang F, Cohen IS: Pacemaker current i(f) in adult canine cardiac ventricular myocytes. J Physiol 1995;485 ( Pt 2):469-483.

6 DiFrancesco D: The role of the funny current in pacemaker activity. Circ Res 2010;106:434-446.

7 Biel M, Wahl-Schott C, Michalakis S, Zong X: Hyperpolarization-activated cation channels: from genes to function. Physiol Rev 2009;89:847-885.

-8 Cerbai E, Mugelli A: I(f) in non-pacemaker cells: role and pharmacological implications. Pharmacol Res 2006;53:416-423.

-9 Sartiani L CE, Mugelli A: The Funny Current in Cardiac Non-Pacemaker Cells: Functional Role and Pharmacological Modulation; in (Das PMR, ed) Modern Pacemakers - Present and Future. 2011, vol. 10.5772/13086p.^pp. 595-610.

10 Fenske S, Mader R, Scharr A, Paparizos C, Cao-Ehlker X, Michalakis S, Shaltiel L, Weidinger M, Stieber J, Feil S, Feil R, Hofmann F, Wahl-Schott C, Biel M: HCN3 contributes to the ventricular action potential waveform in the murine heart. Circ Res 2011;109:1015-1023. 
Semmler et al.: HCN Channels in UTF1-iPS Cell-Derived Cardiomyocytes

11 Shi W, Wymore R, Yu H, Wu J, Wymore RT, Pan Z, Robinson RB, Dixon JE, McKinnon D, Cohen IS: Distribution and prevalence of hyperpolarization-activated cation channel (HCN) mRNA expression in cardiac tissues. Circ Res 1999;85:e1-6.

12 Yasui K, Liu W, Opthof T, Kada K, Lee JK, Kamiya K, Kodama I: I(f) current and spontaneous activity in mouse embryonic ventricular myocytes. Circ Res 2001;88:536-542.

$>13$ Stieber J, Herrmann S, Feil S, Loster J, Feil R, Biel M, Hofmann F, Ludwig A: The hyperpolarization-activated channel HCN4 is required for the generation of pacemaker action potentials in the embryonic heart. Proc Natl Acad Sci U S A 2003;100:15235-15240.

14 Harzheim D, Pfeiffer KH, Fabritz L, Kremmer E, Buch T, Waisman A, Kirchhof P, Kaupp UB, Seifert R: Cardiac pacemaker function of HCN4 channels in mice is confined to embryonic development and requires cyclic AMP. Embo J 2008;27:692-703.

15 Milanesi R, Baruscotti M, Gnecchi-Ruscone T, DiFrancesco D: Familial sinus bradycardia associated with a mutation in the cardiac pacemaker channel. N Engl J Med 2006;354:151-157.

16 Abi-Gerges N, Ji GJ, Lu ZJ, Fischmeister R, Hescheler J, Fleischmann BK: Functional expression and regulation of the hyperpolarization activated non-selective cation current in embryonic stem cell-derived cardiomyocytes. J Physiol 2000;523 Pt 2:377-389.

17 Pfannkuche K, Fatima A, Gupta MK, Dieterich R, Hescheler J: Initial colony morphology-based selection for iPS cells derived from adult fibroblasts is substantially improved by temporary UTF1-based selection. PLoS One 2010;5:e9580.

18 Wei H, Juhasz O, Li J, Tarasova YS, Boheler KR: Embryonic stem cells and cardiomyocyte differentiation: phenotypic and molecular analyses. J Cell Mol Med 2005;9:804-817.

19 Wernig M, Meissner A, Foreman R, Brambrink T, Ku M, Hochedlinger K, Bernstein BE, Jaenisch R: In vitro reprogramming of fibroblasts into a pluripotent ES-cell-like state. Nature 2007;448:318-324.

20 Kolossov E, Bostani T, Roell W, Breitbach M, Pillekamp F, Nygren JM, Sasse P, Rubenchik O, Fries JW, Wenzel D, Geisen C, Xia Y, Lu Z, Duan Y, Kettenhofen R, Jovinge S, Bloch W, Bohlen H, Welz A, Hescheler J, Jacobsen SE, Fleischmann BK: Engraftment of engineered ES cell-derived cardiomyocytes but not BM cells restores contractile function to the infarcted myocardium. J Exp Med 2006;203:2315-2327.

21 Heras-Bautista CO, Katsen-Globa A, Schloerer NE, Dieluweit S, Abd El Aziz OM, Peinkofer G, Attia WA, Khalil M, Brockmeier K, Hescheler J, Pfannkuche K: The influence of physiological matrix conditions on permanent culture of induced pluripotent stem cell-derived cardiomyocytes. Biomaterials 2014;35:73747385.

22 Nguemo F, Fleischmann BK, Gupta MK, Saric T, Malan D, Liang H, Pfannkuche K, Bloch W, Schunkert H, Hescheler J, Reppel M: The L-type Ca2+ channels blocker nifedipine represses mesodermal fate determination in murine embryonic stem cells. PLoS One 2013;8:e53407.

-23 Hamill OP, Marty A, Neher E, Sakmann B, Sigworth FJ: Improved patch-clamp techniques for highresolution current recording from cells and cell-free membrane patches. Pflugers Arch 1981;391:85-100.

$\checkmark 24$ BoSmith RE, Briggs I, Sturgess NC: Inhibitory actions of ZENECA ZD7288 on whole-cell hyperpolarization activated inward current (If) in guinea-pig dissociated sinoatrial node cells. Br J Pharmacol 1993;110:343349.

25 Maltsev VA, Rohwedel J, Hescheler J, Wobus AM: Embryonic stem cells differentiate in vitro into cardiomyocytes representing sinusnodal, atrial and ventricular cell types. Mech Dev 1993;44:41-50.

26 Kuzmenkin A, Liang H, Xu G, Pfannkuche K, Eichhorn H, Fatima A, Luo H, Saric T, Wernig M, Jaenisch R, Hescheler J: Functional characterization of cardiomyocytes derived from murine induced pluripotent stem cells in vitro. Faseb J 2009;23:4168-4180.

-27 MacLean JN, Zhang Y, Johnson BR, Harris-Warrick RM: Activity-independent homeostasis in rhythmically active neurons. Neuron 2003;37:109-120.

-28 Qu J, Kryukova Y, Potapova IA, Doronin SV, Larsen M, Krishnamurthy G, Cohen IS, Robinson RB: MiRP1 modulates HCN2 channel expression and gating in cardiac myocytes. J Biol Chem 2004;279:43497-43502.

29 Sartiani L, Bettiol E, Stillitano F, Mugelli A, Cerbai E, Jaconi ME: Developmental changes in cardiomyocytes differentiated from human embryonic stem cells: a molecular and electrophysiological approach. Stem Cells 2007;25:1136-1144.

30 Accili EA, Proenza C, Baruscotti M, DiFrancesco D: From funny current to HCN channels: 20 years of excitation. News Physiol Sci 2002;17:32-37. 
Semmler et al.: HCN Channels in UTF1-iPS Cell-Derived Cardiomyocytes

31 Barbuti A, Crespi A, Capilupo D, Mazzocchi N, Baruscotti M, DiFrancesco D: Molecular composition and functional properties of f-channels in murine embryonic stem cell-derived pacemaker cells. J Mol Cell Cardiol 2009;46:343-351.

-32 Liu J, Dobrzynski H, Yanni J, Boyett MR, Lei M: Organisation of the mouse sinoatrial node: structure and expression of HCN channels. Cardiovasc Res 2007;73:729-738.

33 Herrmann S, Stieber J, Stockl G, Hofmann F, Ludwig A: HCN4 provides a 'depolarization reserve' and is not required for heart rate acceleration in mice. Embo J 2007;26:4423-4432.

-34 Dobrzynski H, Boyett MR, Anderson RH: New insights into pacemaker activity: promoting understanding of sick sinus syndrome. Circulation 2007;115:1921-1932.

-35 Ludwig A, Budde T, Stieber J, Moosmang S, Wahl C, Holthoff K, Langebartels A, Wotjak C, Munsch T, Zong X, Feil S, Feil R, Lancel M, Chien KR, Konnerth A, Pape HC, Biel M, Hofmann F: Absence epilepsy and sinus dysrhythmia in mice lacking the pacemaker channel HCN2. Embo J 2003;22:216-224.

-36 Barbuti A, Terragni B, Brioschi C, DiFrancesco D: Localization of f-channels to caveolae mediates specific beta2-adrenergic receptor modulation of rate in sinoatrial myocytes. J Mol Cell Cardiol 2007;42:71-78.

-37 Bosman A, Sartiani L, Spinelli V, Del Lungo M, Stillitano F, Nosi D, Mugelli A, Cerbai E, Jaconi M: Molecular and functional evidence of HCN4 and caveolin-3 interaction during cardiomyocyte differentiation from human embryonic stem cells. Stem Cells Dev 2013;22:1717-1727.

-38 Barbuti A, Gravante B, Riolfo M, Milanesi R, Terragni B, DiFrancesco D: Localization of pacemaker channels in lipid rafts regulates channel kinetics. Circ Res 2004;94:1325-1331.

39 Tellez JO, Dobrzynski H, Greener ID, Graham GM, Laing E, Honjo H, Hubbard SJ, Boyett MR, Billeter R: Differential expression of ion channel transcripts in atrial muscle and sinoatrial node in rabbit. Circ Res 2006;99:1384-1393.

40 Yamamoto M, Dobrzynski H, Tellez J, Niwa R, Billeter R, Honjo H, Kodama I, Boyett MR: Extended atrial conduction system characterised by the expression of the HCN4 channel and connexin45. Cardiovasc Res 2006;72:271-281.

41 Much B, Wahl-Schott C, Zong X, Schneider A, Baumann L, Moosmang S, Ludwig A, Biel M: Role of subunit heteromerization and $\mathrm{N}$-linked glycosylation in the formation of functional hyperpolarization-activated cyclic nucleotide-gated channels. J Biol Chem 2003;278:43781-43786.

-42 Hescheler J, Fleischmann BK, Lentini S, Maltsev VA, Rohwedel J, Wobus AM, Addicks K: Embryonic stem cells: a model to study structural and functional properties in cardiomyogenesis. Cardiovasc Res 1997;36:149-162.

43 Mangoni ME, Nargeot J: Properties of the hyperpolarization-activated current (I(f)) in isolated mouse sinoatrial cells. Cardiovasc Res 2001;52:51-64.

44 Maltsev VA, Lakatta EG: Cardiac pacemaker cell failure with preserved I(f), I(CaL), and I(Kr): a lesson about pacemaker function learned from ischemia-induced bradycardia. J Mol Cell Cardiol 2007;42:289-294.

-45 Bogdanov KY, Vinogradova TM, Lakatta EG: Sinoatrial nodal cell ryanodine receptor and $\mathrm{Na}(+)-\mathrm{Ca}(2+)$ exchanger: molecular partners in pacemaker regulation. Circ Res 2001;88:1254-1258.

46 Marger L, Mesirca P, Alig J, Torrente A, Dubel S, Engeland B, Kanani S, Fontanaud P, Striessnig J, Shin HS, Isbrandt D, Ehmke H, Nargeot J, Mangoni ME: Pacemaker activity and ionic currents in mouse atrioventricular node cells. Channels (Austin) 2011;5:241-250.

-47 Ratajczak P, Oliviero P, Marotte F, Kolar F, Ostadal B, Samuel JL: Expression and localization of caveolins during postnatal development in rat heart: implication of thyroid hormone. J Appl Physiol (1985) 2005;99:244-251.

48 Yu X, Guo L, Yin G, Zong X, Ai Y: Effect of non-specific HCN1 blocker CsCl on spatial learning and memory in mouse. J Huazhong Univ Sci Technolog Med Sci 2006;26:164-166.

49 Wahl-Schott C, Baumann L, Zong X, Biel M: An arginine residue in the pore region is a key determinant of chloride dependence in cardiac pacemaker channels. J Biol Chem 2005;280:13694-13700.

-50 Gao Z, Chen B, Joiner ML, Wu Y, Guan X, Koval OM, Chaudhary AK, Cunha SR, Mohler PJ, Martins JB, Song LS, Anderson ME: I(f) and SR Ca(2+) release both contribute to pacemaker activity in canine sinoatrial node cells. J Mol Cell Cardiol 2010;49:33-40.

51 Harris NC, Constanti A: Mechanism of block by ZD 7288 of the hyperpolarization-activated inward rectifying current in guinea pig substantia nigra neurons in vitro. J Neurophysiol 1995;74:2366-2378.

52 Shin KS, Rothberg BS, Yellen G: Blocker state dependence and trapping in hyperpolarization-activated cation channels: evidence for an intracellular activation gate. J Gen Physiol 2001;117:91-101. 